\title{
Trends in mortality from lung cancer in Spain, 1951-80
}

\author{
JESUS VIOQUE AND FRANCISCO BOLUMAR
}

From the Departamento de Salud Comunitaria, Facultad de Medicine, Universidad de Alicante, Alicante, Spain

SUMMARY Lung cancer mortality rates in Spain were calculated for the years 1951 to 1980 . Increasing age-standardised rates for men and levelled off ones for women were observed. Available cigarette consumption data suggest that these current trends could change at the beginning of the next century when there may be a levelling off of male rates and an "epidemic" of female lung cancer.

Lung cancer mortality rates have been increasing in the majority of developed countries in the last few decades, following by about 20 years a parallel trend in cigarette smoking. ${ }^{2}$ In recent years, the rate of increase has been greater in females than in males, reflecting the growing popularity of cigarette smoking among women over the past 20 to 30 years. $^{3}$

In order to assess lung cancer mortality and patterns of cigarette smoking, this paper presents the results of a study carried out in Spain on mortality due to lung cancer from 1951 to 1980 . Cross-sectional rates by age and sex were used. The trend of per capita consumption of cigarettes from 1957 to 1982 is presented as well as the current patterns of cigarette smoking in Spain.

\section{Material and methods}

The data for deaths attributed to lung cancer were obtained from Spain's National Institute for Statistics (INE) for the years 1951-80 (6th and 7th Revision International Classification of Diseases, codes 162163; 8th and 9th Revisions, code 162). ${ }^{4}$

Death rates per 100000 inhabitants were calculated using decennial census population figures. Intercensal populations were estimated by linear interpolation. Age-standardised lung cancer mortality rates were calculated by the direct method, using the 1970 Spanish population as the standard population. The age-specific lung cancer death rates for the 10-year age categories 20-29, 30-39, . 60-69 and 70+ years were calculated for both sexes during the time period referred to. These data were then used to compute age curves for year-of-birth cohorts.

Statistical tests were performed to determine whether time trends of lung cancer mortality were statistically significant.

The trend of per capita consumption of cigarettes from 1957 to 1982 was derived from the statistics published by the Spanish National Monopoly of
Tobacco. ${ }^{5}$ The data referring to the current patterns of cigarette smoking in Spain were obtained from a national sample-based survey conducted by the INE in 1978 on a sample of 5107 people representative of the general Spanish population. ${ }^{6}$ In this survey, persons classified as ex-smokers were those who having smoked in the past did not smoke when the survey was carried out. No more detail is obtainable from the survey.

Results

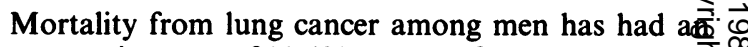
average increase of $11.4 \%$ per year from 1951 to $198 \overline{\theta^{2}} \stackrel{\infty}{.}$

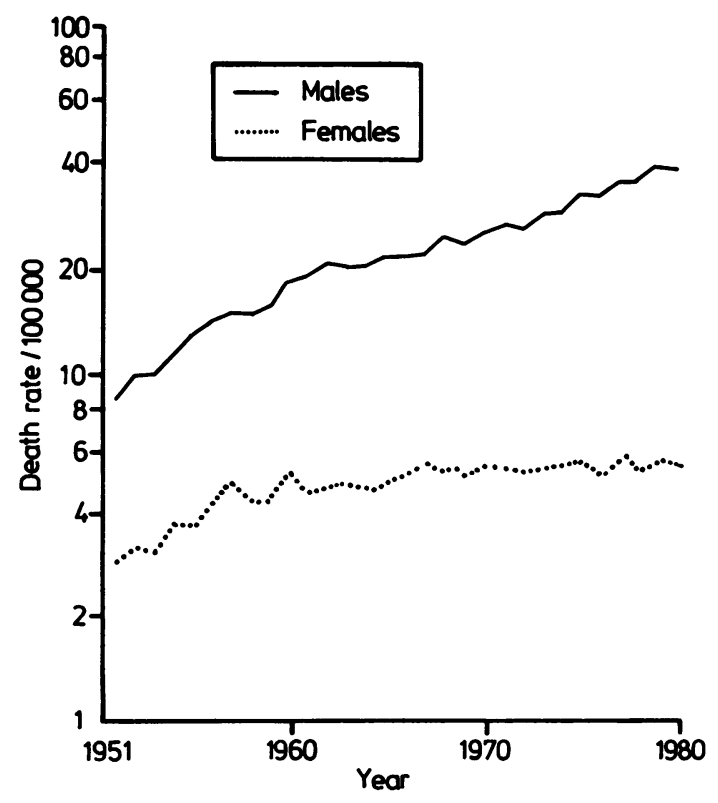

Fig 1 Age-adjusted lung cancer mortality rates among men and women in Spain, 1951-80. 
Table 1 Age-adjusted (total) and age-specific lung cancer mortality per 100000 among men and women in Spain, 1951-80

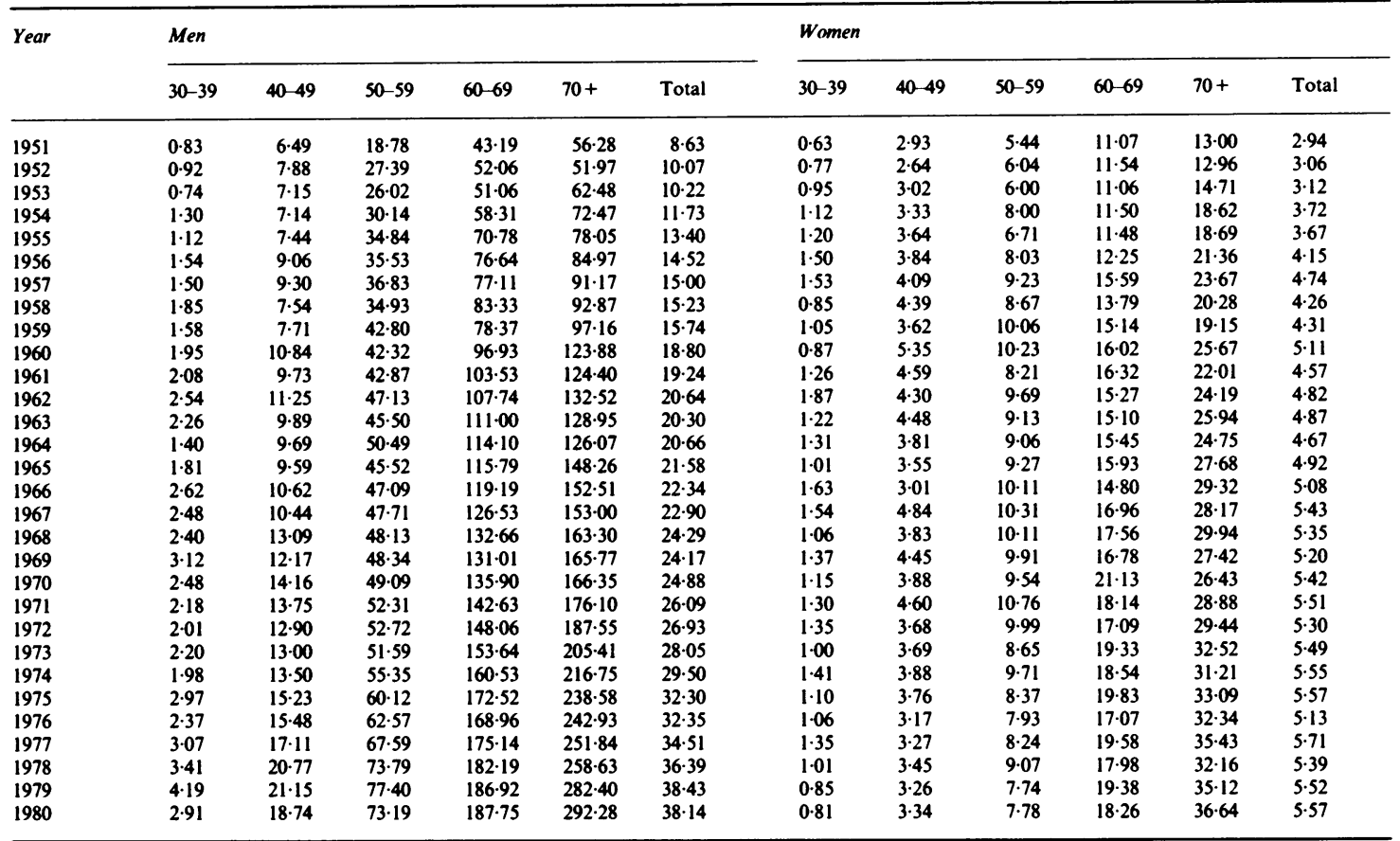

in Spain (fig 1 and table 1). The total increase throughout the period has been $342 \%$, which is reflected in an increasing trend (see fig. 1) which reached statistical significance.

Lung cancer mortality rates for women have also risen during this period, with a total increase of $89 \%$, the trend being also statistically significant (table 2 ). However, the trend showed two different phases: in the first one, from 1951 to 1960 , the rates increased at about $7.4 \%$ per year, whereas in the second phase, from 1961 to 1980 , the rates levelled off.

The different evolution of the rates for each sex has brought about a change in the sex ratio: while the male

Table 2 Correlation coefficients for lung cancer mortality rates, Spain, 1951-80.

\begin{tabular}{llll}
\hline & & Men & Women \\
& & $r$ & $r$ \\
\hline \multirow{2}{*}{ Age-adjusted rate } & $0.9999 *$ & $0.8988 *$ \\
& $20-29$ & $0.5124 * *$ & n. s. \\
Age-specific & $30-39$ & $0.8512 *$ & n. s. \\
rates & $50-49$ & $0.9357 *$ & n. s. \\
& $50-69$ & $0.9650 *$ & $0.3805 * *$ \\
& +70 & $0.9949 *$ & 0.8984 \\
& $+0.9951 *$ & $0.9655 *$ \\
\hline
\end{tabular}

* $\mathrm{p}<0.0001 \quad * * \mathrm{p}<0.01 \quad * * * \mathrm{p}<0.05$

$r=$ Pearson's correlation coefficient rates were three times higher than the female ones in 1951 , in 1980 they were almost seven times higher.

Figure 2 and table 1 show the age-specific mortality rates for each sex. Women over 60 and all the male age groups display upward trends. Nevertheless, women in the 30-59 age group also show a rising trend from 1951 to 1960 , when it levels off and even decreases towards the end of the period.

The lung cancer mortality rates for Spanish men and women are illustrated by cohorts in figure 3 . For men, mortality increased linearly with age and was consistently higher in the later born cohorts, except for the last cohort born around 1956 which showed a lower rate than the preceding one. This rate, however, was based on few cases. For women, mortality only increased until the cohort born around 1916, showing lower rates for the later born cohorts.

The trend of per capita consumption of cigarettes from 1957 to 1982 is shown in figure 4. This trend has been increasing steadily throughout the period 195780 , although a levelling off with fluctuations is apparent at the end of the period. Unfortunately, it has been impossible to get data for cigarette consumption before 1957 from the Spanish National Monopoly of Tobacco.

The data from table 3 show that the current prevalence of smoking in men was not appreciably influenced by age up to age 65 . The reported 


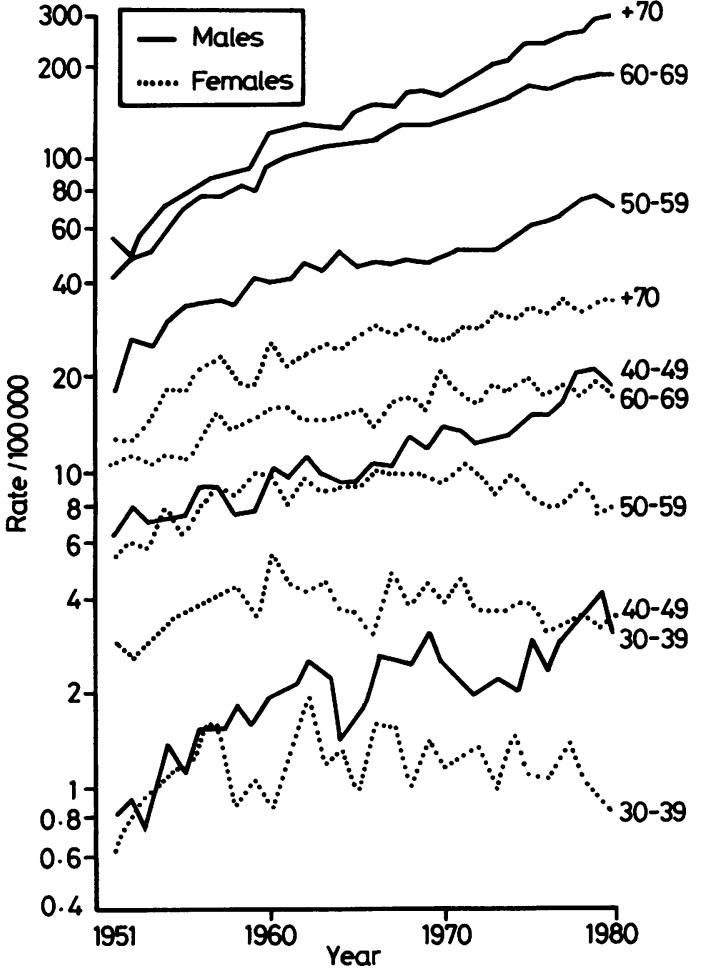

Fig 2 Age-specific lung cancer mortality rates among men and women in Spain, 1951-80.

prevalence of smoking in women was higher in the younger age groups, reflecting that smoking has become widespread among women only in the last one or two decades, although the possibility that the prevalence of smoking among women aged 25 and over has been underestimated due to some reluctance to admit to smoking on their part cannot be ruled out.

Finally, table 4 shows the number of cigarettes smoked per day in every age group. Smoking patterns among men highlight the point that from the age of 25 until 65 the percentage of smokers who smoke more than 20 cigarettes per day exceeds the percentage of those who smoke less than 20 cigs/day. This does not apply to women who reported a smaller number of cigarettes smoked daily on average.

\section{Discussion}

The data from this study show an upward trend of lung cancer mortality in men and a levelled off trend in women in Spain. These patterns are similar to those seen in Italy, ${ }^{7}$ where an upward trend also occurs in men, while the trend for women has been quite steady for the period 1955-78, and quite different from those in other developed countries in which female rates have been increasing during the period of reference. ${ }^{28}$

There is no evidence in our study that these trends will change in the short term. Thus, the male generation born around 1946 appears to maintain the highest levels of mortality rates, and all age groups show clear upward trends. For women, there is also an increase in the early cohort values. However, the peak is reached in the cohort born around 1916, and no clear upward trend of lung cancer mortality among young women is evident yet.

Although the data on per capita consumption of cigarettes are not available by sex, its trend is mainly determined by male consumption in Spain. As was shown in fig 4, this trend has levelled off from 1975, in spite of the fact that in the last few years smoking hase become widespread among women. Both this fact and the data of the current prevalence of smoking in men support the idea that tobacco consumption is levelling off or decreasing in men at the present time and, since the effects of smoking in a population only become evident two or three decades after its diffusion, lung cancer mortality in men will probably follow a parallel trend in 20 or 30 years. Perhaps it could be considered that the decline in mortality in the latest male cohort, born around 1956, upholds this idea.

It is unfortunate that data concerning cigarette smoking are not available before 1957 in order to assess the potential impact of cigarette smoking on the

Table 3 Estimated prevalence (\%) of cigarette smoking in Spain according to age and sex. Data from a sample-based survey conducted in 1978 by Spain's National Institute for Statistics (INE)

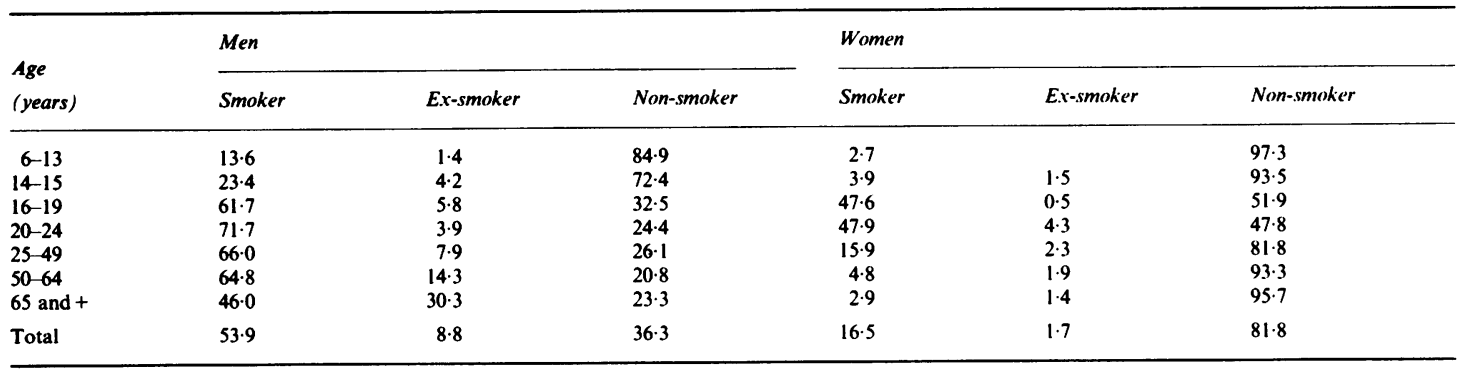


Trends in mortality from lung cancer in Spain, 1951-80

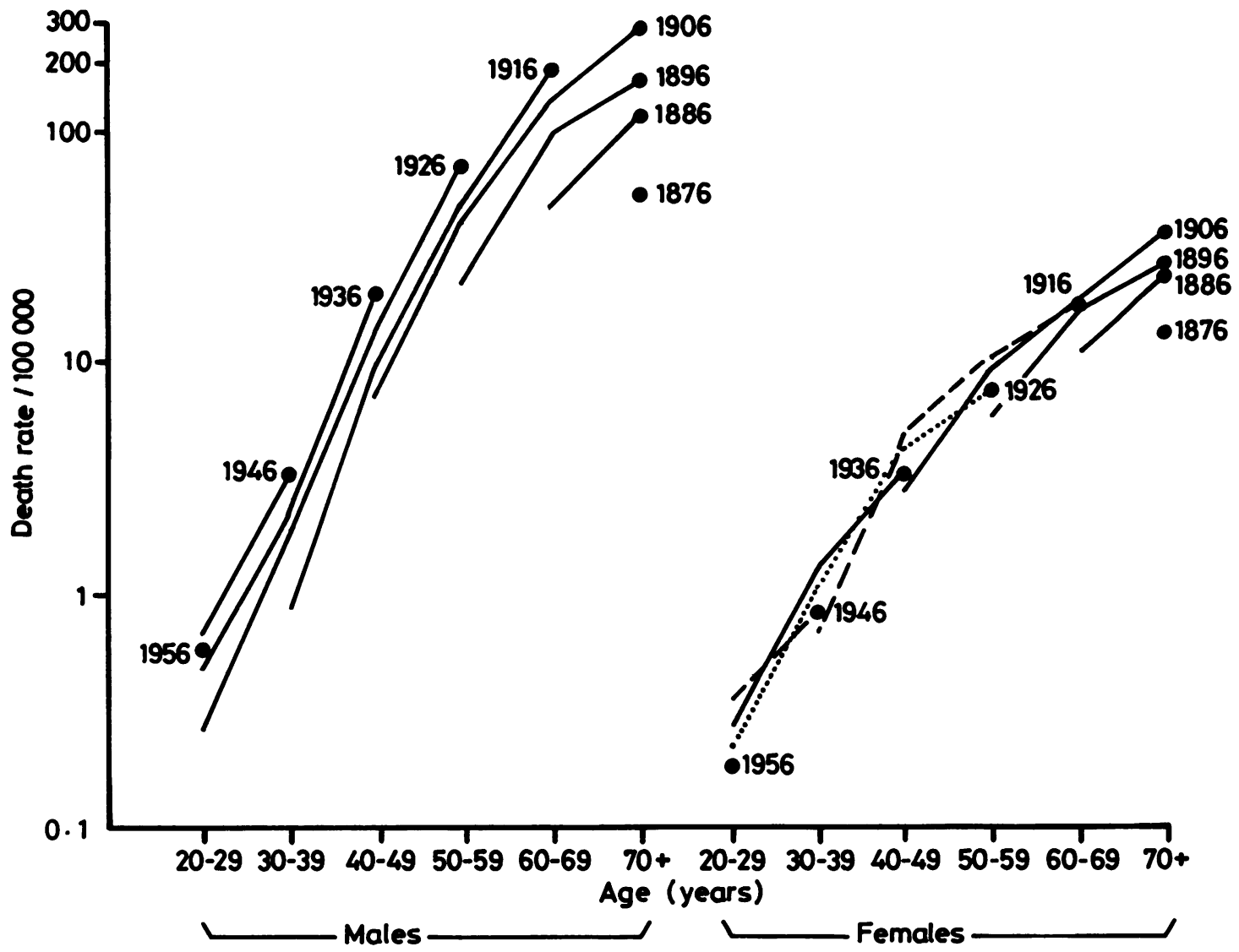

Fig 3 Age-specific lung cancer mortality rates, 1951-80, among men and women in Spain for selected year-of-birth cohorts.

Table 4 Estimated distribution (\%) of cigarette smokers according to number of cigarettes smoked, age, and sex. Data from a sample-based survey conducted in 1978 by Spain's National Institute for Statistics (INE)

\begin{tabular}{|c|c|c|c|c|c|c|}
\hline \multirow{3}{*}{$\begin{array}{l}\text { Age } \\
\text { (years) }\end{array}$} & \multicolumn{6}{|c|}{ Number of cigarettes smoked per day } \\
\hline & \multicolumn{3}{|l|}{ Men } & \multicolumn{3}{|c|}{ Women } \\
\hline & $0-20$ & $20+$ & NR & $0-20$ & $20+$ & NR \\
\hline $6-13$ & 83.04 & 2.85 & $14 \cdot 11$ & $49 \cdot 48$ & - & 50.52 \\
\hline $14-15$ & $89 \cdot 18$ & 9.31 & 1.512 & 81.01 & - & 18.95 \\
\hline $16-19$ & $79 \cdot 29$ & $16 \cdot 39$ & $4 \cdot 42$ & $85 \cdot 43$ & $10 \cdot 12$ & 4.45 \\
\hline $20-24$ & $51 \cdot 14$ & $46 \cdot 10$ & 2.76 & 73.60 & 23.64 & 2.76 \\
\hline $25-49$ & $36 \cdot 28$ & $61 \cdot 55$ & $2 \cdot 17$ & $68 \cdot 13$ & $25 \cdot 14$ & 6.73 \\
\hline $50-64$ & 40.37 & 57.68 & 1.95 & 71.62 & 21.68 & 6.7 \\
\hline+65 & $27 \cdot 21$ & $26 \cdot 77$ & $45 \cdot 32$ & 35.74 & $7 \cdot 52$ & $56 \cdot 74$ \\
\hline
\end{tabular}

$\mathbf{N} \mathbf{R}=$ non response

age groups $30-59$ during the period $1951-60$. To our knowledge, these data might suggest that some other factors could have acted upon those age groups before the period of reference.

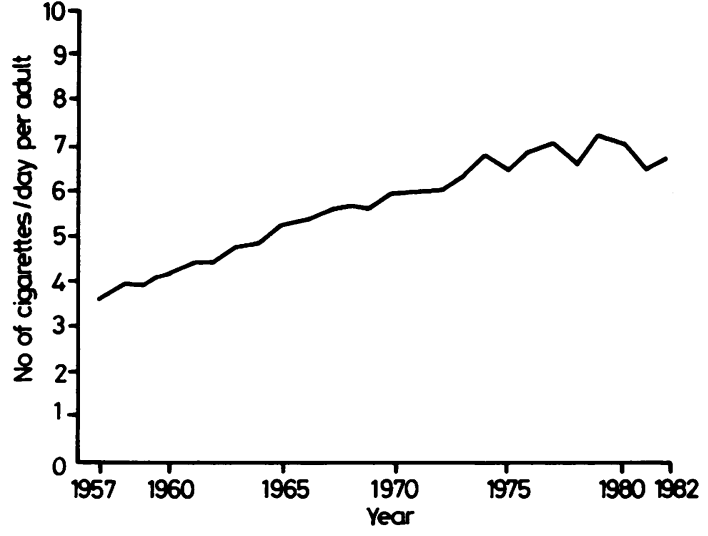

Fig 4 Mean daily sales of cigarettes per Spanish adult over 15 years of age, 1957-82

There is some evidence from the observed pattern of current cigarette smoking (table 3 ) to suggest a recent 
and massive spread of the habit in women. As the smoking habits in early adult life are strong determinants of the risk in subsequent life, ${ }^{2}$ we believe that an "epidemic of lung cancer in women" can be expected in the first or second decades of the 21 st century in Spain.

In conclusion, we believe that lung cancer mortality trends very similar to the ones occurring in the USA and the UK at present could happen in Spain at the beginning of the next century. Nevertheless, some facts such as the reduction in average tar and nicotine yields over recent years, the smaller number of cigarettes smoked on average (also inhaled less deeply), and the effects of campaigns against smoking could change or prevent the expected increase of lung cancer mortality in women and the levelling off in men.
References

${ }^{1}$ Blot WJ, Fraumeni J Jr. Changing patterns of lung cancer in the United States. Am J Epidemiol 1982; 115: 664-73.

${ }^{2}$ Doll R, Peto R. The causes of cancer. Quantitative estimates of avoidable risks of cancer in the United States today. Oxford: Oxford University Press, 1981.

${ }^{3}$ Kristein MN. Japanese lung cancer mortality rates, $1947-$ 80 and per capita cigarette consumption in Japan 5. Int J Epidemiol 1986, 15, 140-1.

${ }^{4}$ INE. Movimientos naturales de la población, 1951-1980 Madrid.

${ }^{5}$ Actualidad Tabaquera. El consumo de tabaco en España. Series Históricas. 1957-1982. Tabacalera SA. Servicio de Estudios. Madrid no. 16.

${ }^{6}$ BES Ministerios de Sanidad y Seguridad Social. Dirección General de Salud Pública. 1981, 1502, 289-291.

${ }^{7}$ La Vecchia C. Patterns of cigarette smoking and trends in lung cancer mortality in Italy. J Epidemiol Commun Health 1985, 39, 157-64.

${ }^{8}$ Horm JW, Kessler LG. Falling rates of lung cancer in men in the United States. Lancet, 1986, i: 425-6. 